\title{
Psychological refractoriness and the organization of step-tracking responses*
}

\author{
ROBERT GOTTSDANKER $\dagger$ \\ Eniversity of California, Santa Barbara, California 93106
}

\begin{abstract}
Three young men were given the step-tracking task of pushing a slider to either a near or a far target lamp as soon as one came on. Occasionally, the alternative lamp replaced the initial one after it had been on for $50 \mathrm{msec}$, calling for either curtailment or extension of the initial command. This new stimulus information led to the modifying of response on a majority of trials. Its first discernible effect occurred without any PR (psychological refractoriness) delay. In some cases, the response appeared to be influenced from its onset by the second signal. More of ten. modification appeared later. Typically. the response was inadequate relative to the new command, or distorted. Effects of the initial command evidently persisted, either in neural organization or in actual execution. Step-tracking responses are thus vulnerable, yet resistant to modification. It is reasonable that in continuous tracking the operator would avoid making effortful. inadequate modifications. Hence. his performance could be described as voluntarily intermittent. The usual PR delay found on dual keypressing tasks cannot be attributed to limitations in capacity for identifying signals or even in "selecting" a response. It is suggested that the organizational process required for the first response interferes with another such process.
\end{abstract}

In an earlier study on the question of $P R$ (psychological refractoriness) of step-tracking responses (Gottsdanker. 1966). it was found that a response to a signal typically was modified by a superseding command which was given sufficiently early. Two hypotheses seemed tenable for explaining the findings. One was that the second signal gives rise to a second response which overlaps the first response in time. The other is that there is a unitary response determined jointly from the outset by the two signals. If the response starts as though there had been no second signal, in accordance with the first hypothesis, the instant at which it begins to diverge from the simple response would mark the start of the second response. The time between the onset of the second signal and the start of the second response would be the RT (reaction time) to the second signal. This RT could then be measured to find whether it had normal value or one lengthened by PR. On the other hand, if the effect of the second signal appears from the outset, then it could be said to have influenced the response in even less than the normal RT instead of being subjected to PR.

In the present study, an attempt was made to resolve this issue by making more detailed measurements of responses. This was done by obtaining continuous

*This research was supported by Grant MH-10447 from the National Institute of Mental Health. Additional funds for data analysis were provided by a faculty research grant from the University of California. Generous contributions in the use of facilities and of expert assistance were provided by the Health Sciences Computing Facility and the Brain Research Institute at the University of California, Los Angeles, and by the Computer Center at the University of California, Santa Barbara. The writer is especially grateful to Thomas C. Way for his assistance in every phase of the project. Judith Bruckner developed the critical computer programs. Many students gave valuable help at one time or another. Chief among them were: Steven Slater, Linda McDivitt, Camille Gilbert, and Nancy Dierdorff. measures of velocity and acceleration in addition to displacement. These "more intimate" measures should be useful for locating points of divergence, if they exist. A plan for analysis of the present data has already been described (Gottsdanker, 1967). As will be seen, actual work with the data showed that not all aspects of the plan could be carried through. In compensation, much was revealed about step-tracking responses which had not been envisaged. Even the questions which motivated the study are shown to be rather inadequate. They assume a rigid organization of response when there is no correcting signal and also a uniform effect of the correcting signal.

\section{METHOD OF EXPERIMENTATION}

\section{Task}

\section{Uncorrected trials}

A sliding pointer was moved by $\mathrm{S}$ along a table top away from himself to whichever of two target lamps lighted, one centered $6.2 \mathrm{~mm}$ from the center of the home lamp and one $15.9 \mathrm{~mm}$. All trials started with the home lamp lighted. Return movements to that position were of no interest as they could be anticipated, and often took place before the return-to-home signal occurred

Simultaneous with the lighting of one of the two target lamps. selected at random, the home lamp would be turned off. The target lamp would remain on for $1 \mathrm{sec}$ and then be replaced by the home lamp, also for $1 \mathrm{sec}$, to which $S$ would return the pointer and get ready for the next trial. Thus, there was a choice between a near and far target every $2 \mathrm{sec}$. S's hand movement activated three transducers. A miniature linear accelerometer served as the handle for the pointer, and to it were attached at the far end the cores of two linear differential transformers. which provided displacement and velocity outputs. The arrangement is shown in Fig. 1.

\section{Corrected trials}

On this kind of trial, the selected target lamp would stay on for only $50 \mathrm{msec}$ and then be replaced by the alternative target 


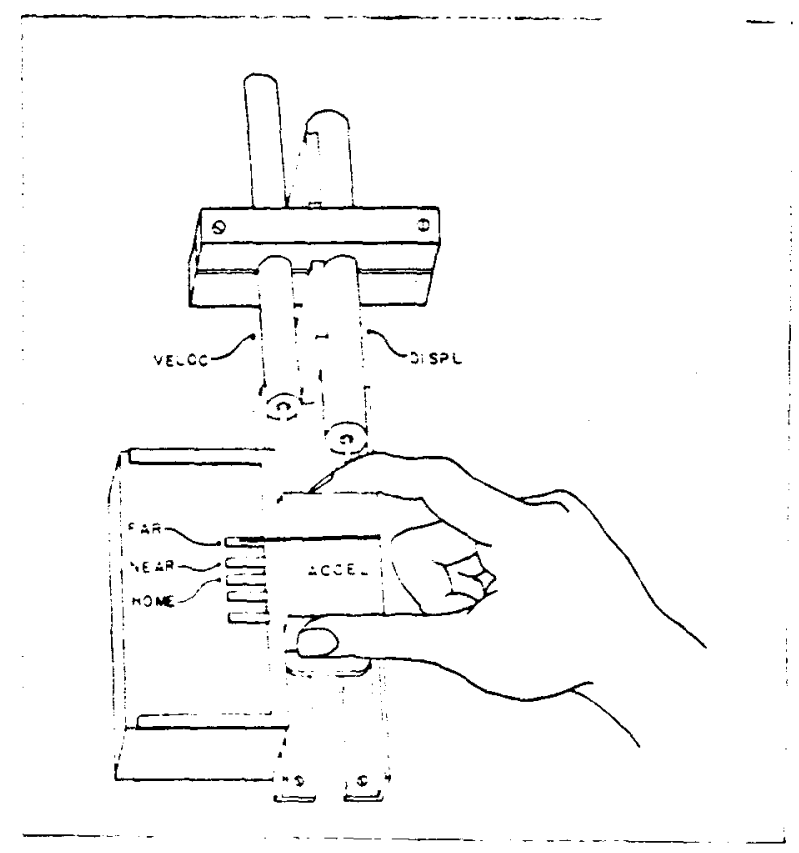

Fig. 1. The experimental arrangement.

lamp for the remainder of the second. These corrected trials. then. constituted either a near-far extension of the initial command if the near lamp was replaced by the far lamp) or a far-near curtailment if the far lamp was replaced by the near lamp). On the experimental blocks of trials, $90 \%$ were uncorrected and a random $10 \%$ were corrected. On the control blocks of trials, all were uncorrected.

When $S$ performed under the experimental condition. he was instructed to respond to each signal as it occurred. neither holding back to see whether there would be a correction nor delaying his reaction to the correction in order to complete his initial response. Because of the importance of S's understanding of the task. the instructions given him before his first block of experimental trials are reproduced: "Today the way in which the lights come on will be a little bit different. On about 10 s of the trials. when the near or far light comes on, it will do so only momentarily. Exactly as it goes off. the other light (far or near) will come on. Such special trials will occur at random. The other $90^{\circ}$ of the trials will be just as before. Your task remains basically the same. When a light comes on. start your response as soon as you can and more as quickly as you can. If. on a trial where the momentary light is replaced. the second light has already come on before you are able to start your response, move directly to it. If the second light comes on after your hand has already started to move to the first light. change your response immediately so that you are responding as soon as possible to the second light. In other words, you should make the greatest effort to put your pointer on the light that is on at the moment. Remember that these special trials come at random. so don't try to guess when they will occur. Also, don't slip into the habit of waiting to see whether the trial will be a special one. We know how quickly you are able to respond. Any hesitation or even slight tendency to wait will show up at once."

\section{Procedure}

\section{Selection of $S s$}

A pilot $S$. called $S 1$. Was a volunteet from $E^{\prime}$ s class in experimental psychology. Experience with this $S$ was used to guide the further procedures. Also. the methods for andyzing responses with the computer were worked out on his data. However. his data were not used in the results presented in this paper. In order to obtain the other Ss. a larger number were screened. Only right-handed young men were solicited. Three Ss were found who snowed a serious attitude and stability in "quickness of resporse." This measure was the time interval between the onset oi a target and the instant the movement went beyond the home position. It doubtless reflects both RT and speed of movement. The $S s$ were paid $\$ 2$ an hour. They ranged in age from 19 to 22 .

\section{Training}

Ss 2. 3. and 4 were given a program of training with the goal of stabilizing their individual modes of response: it was especially. desired that they respond in the same way on blocks of experimental trials as on control blocks. The first step was to give each $S$ extensive practice under the control condition. Each was given practice in daily sessions of about $50 \mathrm{~min}$. During a session. eight blocks of 100 trials were presented with a rest of 2 min between blocks. There were either four or five of such sessions for each $S$ over a period of either 6 or 7 days. Records were kept of mean quickness of response so that $S$ 's progress tow ard a rapid. stabilized response could be assessed. Also. responses were monitored in respect to displacement. velocity. and acceleration on an ink-writing oscillograph. Ss were encouraged to make brisk, positive responses.

In the next four or five training sessions, extending over a period of 8 days, they were given the control and experimental conditions in different sessions or half sessions to ascertain that there was no difference in quickness of response under the two conditions. As a result of the training. S 2 stabilized at a mean quickness value of about $215 \mathrm{msec}$ after starting at $235 \mathrm{msec}:$ S 3 went down from $205 \mathrm{msec}$ to $185 \mathrm{msec}$. and $\mathrm{S} 4$ from $260 \mathrm{msec}$ to $225 \mathrm{msec}$.

\section{Test Sessions}

Following the training. there were six test sessions. each consisting of eight blocks of 100 trials on which data were collected for analysis. The sessions occurred over a period of 8 days. On the second and fifth sessions, $\mathrm{S}$ s were tested under the control condition (called Control 1 and 2), and on the other four sessions. they were tested under the experimental condition. An FII tape recorder was used to register the output from the displacement and acceleration transducers as well as the signal information. These trials were also monitored on the ink-writing oscillograph.

\section{Apparatus}

The experiment was conducted in a sound-shielded room (IAC 400), with ambient illumination reduced to about $10 \mathrm{fL}$. The table on which the seated $\mathrm{S}$ moved his controls was sturdy. cross-braced. and bolted to the concrete floor. Neon lamps (GE X5) were used to end-light Plexiglas strips, $2.5 \mathrm{~mm}$ in width. the top edges of which constituted the target and home positions. The accelerometer (Donner $D C \pm 5 \mathrm{~g}$. Model 4310 ). which also served as the handle for the pointer. was $50 \mathrm{~mm}$ in width. It slid in a polished aluminum trough and was covered with velvet at all points of contact with the trough. At one end of the accelerometer were attached the sliding cores of the displacement and velocity transducers (Sanborn linear differential transformers. 24DCDT-2000 and LVin 6L Vi). A great deal of attention was paid to the smoothness and freeness of operation of the control. The pointer was a brass wire. $1.5 \mathrm{~mm}$ in width. which was fastened to the accelerometer.

Programming was accomplished by means of a system of logic units (BRS 100 series). pulsed by a 1.000 sec precision clock (BRS Mit). On aich trial of a block. S"s response would stop two s-kC ring counters. The position of one Hould iclect which 
Fig. 2. A sample far response. Direct tracings from the $F M$ tape recording as shown above: the computer printout of the digitized values is presented below.
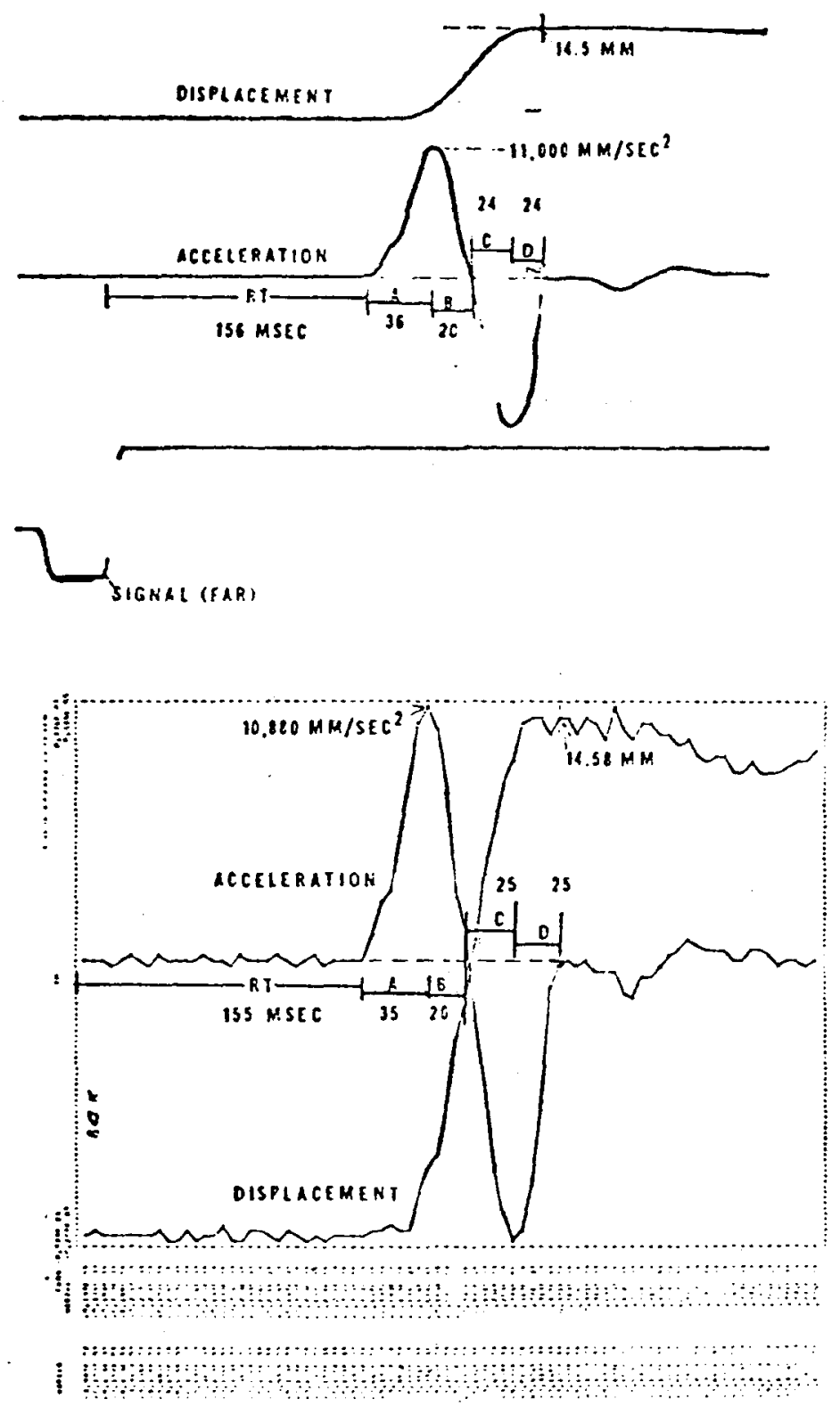

of the two target lamps would be lighted on the next trial. The other selected the $10 \%$ of the trials, under the experimental condition, on which there was a correction.

A four-channel $1 / 4$-in. FM recorder (Sanborn 2004) registered the data. On one channel was recorded the signal information; on two others, after suitable attenuation, were the outputs from the displacement and acceleration transducers. The fourth channel was used to provide correction on the data channels for any irregularity in the speed of recording (flutter compensation). Graphic records at low speed were made on the ink-writing oscilloscope (Beckman Type RM dynograph) for purposes of monitoring and included the velocity information. Occasionally, the recorder was operated at high speed to check on response forms.

\section{Treatment of Data ${ }^{3}$}

After several transformations, the information on signals and responses was stored in digital form on a magnetic disk. Analysis was then undertaken with an IBM 36065 computer. Figure 2 presents the same far response in its analog form traced on the ink recorder from the FM tape and as a digitized computer printout. In the upper graph, the amplitudes of maximum displacement and peak positive acceleration were determined by eye, as were the five intervals to the salient points of the response. In the lower graph, these values were found by using a computer program in which times were located to the nearest $5 \mathrm{msec}$.

A velocity curve was obtained for each response by integrating the acceleration curve. When this curve, in turn, was integrated, it provided a constructed displacement curve which could be compared with that actually recorded from the displacement transducer as a check on linearity and calibration. In all, nine measures were obtained on each trial. The four amplitude measures were: maximum displacement, peak velocity, peak positive acceleration, and peak negative acceleration. The four 


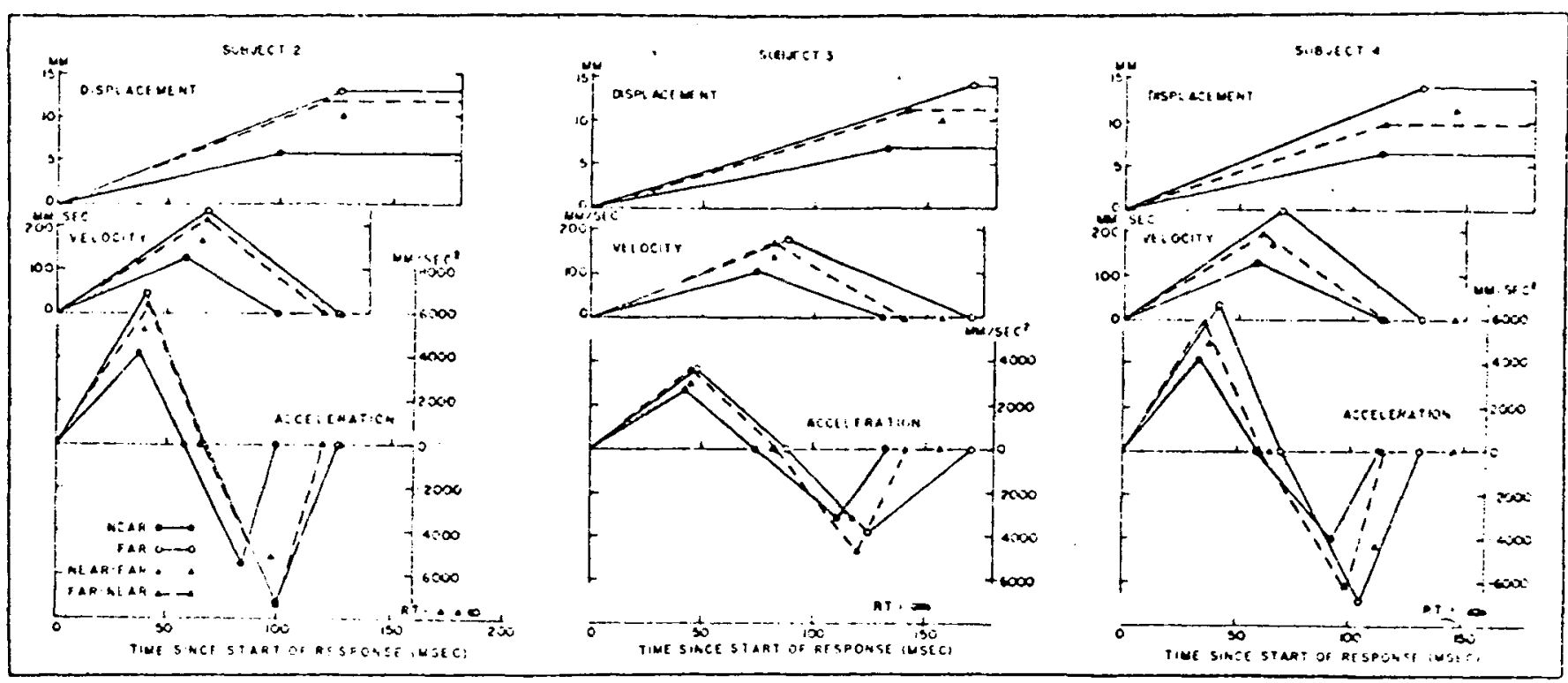

Fig. 3. "Stick figures" representing the mean values on experimental trials on each of the amplitude and time measures.

time measures were RT if from the onset of the first or only signal to the onset of the response): $A$. onset of response to instant of peak positive acceleration: $B$. from then to instant of peak velocity (which is also the first return to zero acceleration); $C$. from then to peak negative acceleration: $D$, from then to maximum displacement (next return to zero acceleration).

\section{RESULTS}

Since the concern of this study is with what happened on the corrected trials. the data discussed will be from the blocks of experimental trials. Mode of response. including RT, for uncorrected trials was essentially the same on the experimental and control blocks. The overall RT on both types of uncorrected trial were as follows: S 2 experimental. $181 \mathrm{msec}$ : control, $182 \mathrm{msec}$; S 3 experimental, $147 \mathrm{msec}$ : control. $145 \mathrm{msec} ; \mathrm{S} 4$ experimental. $157 \mathrm{msec}$ : control, $153 \mathrm{msec}$. No effect on other measures could be attributed to the occasional corrected trial.

\section{Mean Values on the Four Types of Trial}

The "stick figures" in Fig. 3 represent the mean values on each of the nine amplitude and time measures obtained. For each $S$, the top set of curves indicates the measures on displacement, the center set those on velocity, and the bottom set those on acceleration. Also. along a line at the very bottom is represented the mean RT on each type of trial. Table 1 presents the summary data, which were subjected to further analysis. The total number of each type of uncorrected trial for a $S$. near or far, ranged between 1.343 and 1.449 ; the total number of each type of corrected trial, near-far or far-near. ranged between 132 and 166. Differences are largely due

Table 1

Data Summary for Experimental Trials

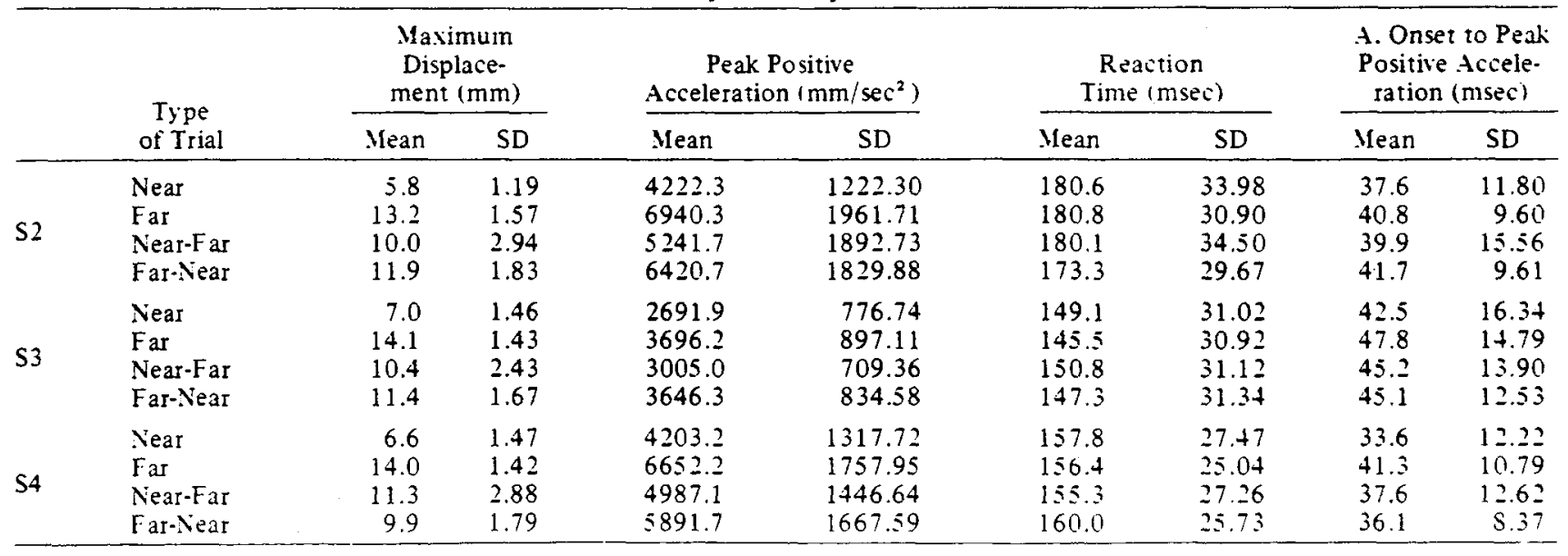


to the method of chance selection of conditions, although there were a few mishaps. Trials were rejected if a computer determination could not be made on all of the measures. The number rejected on a given type of trial ranged between $0.42 \%$ and $5.42 \%$ of the total. There were two reasons for rejection: the response did not start clearly or it was not finished within $400 \mathrm{msec}$ after the onset of the signal. It was ascertained that wherever the elimination was selective, it did not materially affect the analyses.

It is seen that maximum displacement is greater on near-far trials than on near trials and that it is smaller on far-near trials than on far trials in each of the six comparisons. To be sure, there are noteworthy variations in amount of difference. ${ }^{2}$ In five of the six comparisons, the differences described for maximum displacement also hold for peak positive acceleration. For S 3, the difference between far and far-near is small. Obviously, the responses must have differed before the peaks were reached, between 33 and 48 msec after the onsets. ${ }^{3}$ RT did not vary systematically; there was no tendency toward a higher value on corrected trials.

\section{Classification of Responses: Displacement-Duration Scatter Diagrams}

Figure 4 presents $S 4$ 's plots of displacement against total duration of response $(A+B+C+D)$. In the top portion is shown a random sample of about 150 near trials and about the same number of far trials, i.e., about the same as the number of corrected trials of each type. The convex contour lines were placed to enclose about 95\% of the trials on previously drawn samples of the same size of near and of far trials. It can be seen that less than $10 \%$ of the trials in the new samples fall outside the appropriate contours, but that only a few of the responses are frank errors to the extent of making the appropriate response to the alternative signal.

In the center diagram are shown the near-far trials, with the near and the far contours transferred from the diagram on the left. Far-near trials are represented in the bottom portion. For S 4, 24\% of the near-far responses fell within the near contour and are classed as unaffected trials. Within the far contour, there are $27 \%$; these are classed as responses showing the typical far organization. A combined contour is formed with the dotted lines to divide the responses modified in organization. Those within the contour show about the same duration-displacement pattern as either near or far responses; those to the right show a stretching out of duration in relation to displacement. Thus, of the remaining values, those with neither near nor far organization are $27 \%$ of responses between contours and $22 \%$ which have exaggerated values of duration.

Similar classifications have been made for the other Ss on near-far trials and for all three Ss on far-near trials. The results are summarized in Table 2 along with the comparative data on near trials and on far trials.
In every case except one, $\mathrm{S}$ was shown to have been influenced by the second signal more often than not. That exception is $\mathrm{S} 2$ on far-near trials, where $77 \%$ remained classified as far. The next highest value is $27 \%$.

In every case, there were more modified responses which did not fit into the second signal classification than those which did. The substitute response was the exception, not the rule. The highest percentage of modified responses falling within the second signal contour was 46 , i.e., $35 \%$ of a total of $76 \%$ (S 2 on near-far): the lowest was $11 \%$ (S 3 on far-near). While Ss 2 and 4 quite often showed dramatic increase in duration on near-far trials, S 3 did not often do so.

Both Ss 3 and 4 were more successful in modifying their responses on far-near trials than was $S 2$, with $S 4$ even being able to achieve the near pattern on $30 \%$ of his responses. Nevertheless, even $\mathrm{S} 2$ showed some modification on $23 \%$ of his responses. Only S 3 showed an appreciable number of responses with marked reduction of duration. Apparently, it is easier to stretch a response than to shrink one.

It should be noted that the percentages given for trials showing no modification or complete substitution of the pattern appropriate to the second signal are maximum estimates. The corrected trials tend to fall unevenly within the contours. For example, S 4's far-near responses which fall within the far contour are mostly near the boundary. Thus, it would be safe to say that it is typical for the response to be different from those made to either signal alone. A near-far response with a very long duration must be due to a correction to an initial plan by S. ${ }^{4}$

\section{Classification of Responses: Early and Final Effects of the Second Signal}

In Figure 3, it appears that the effect of the second signal increases during the course of the response. The hypothesis of such an increase was tested as follows: First, a fourfold table was set up for each $S$ on each type of corrected trial, near-far or far-near, in respect to peak positive acceleration and maximum displacement. Each near-far trial was classified according to whether it fell above or below the S's median for near trials on both acceleration and displacement. Similarly, far-near responses were compared with S's median on far trials. Finally, the null hypothesis was tested (on near-far trials) that changes from below the near median to above the near median between peak positive acceleration and maximum displacement were not more frequent than the reverse direction of change. For far-near trials, the hypothesis was that above far median to below far median changes were no more frequent than the reverse.

These cross-classifications are shown in Table 3. Near-far trials are on the left and far-near trials on the right. On near-far trials for S 2, there were 47 changes from below to above the near median, as compared with only 5 from above to below. On far-near trials, there 


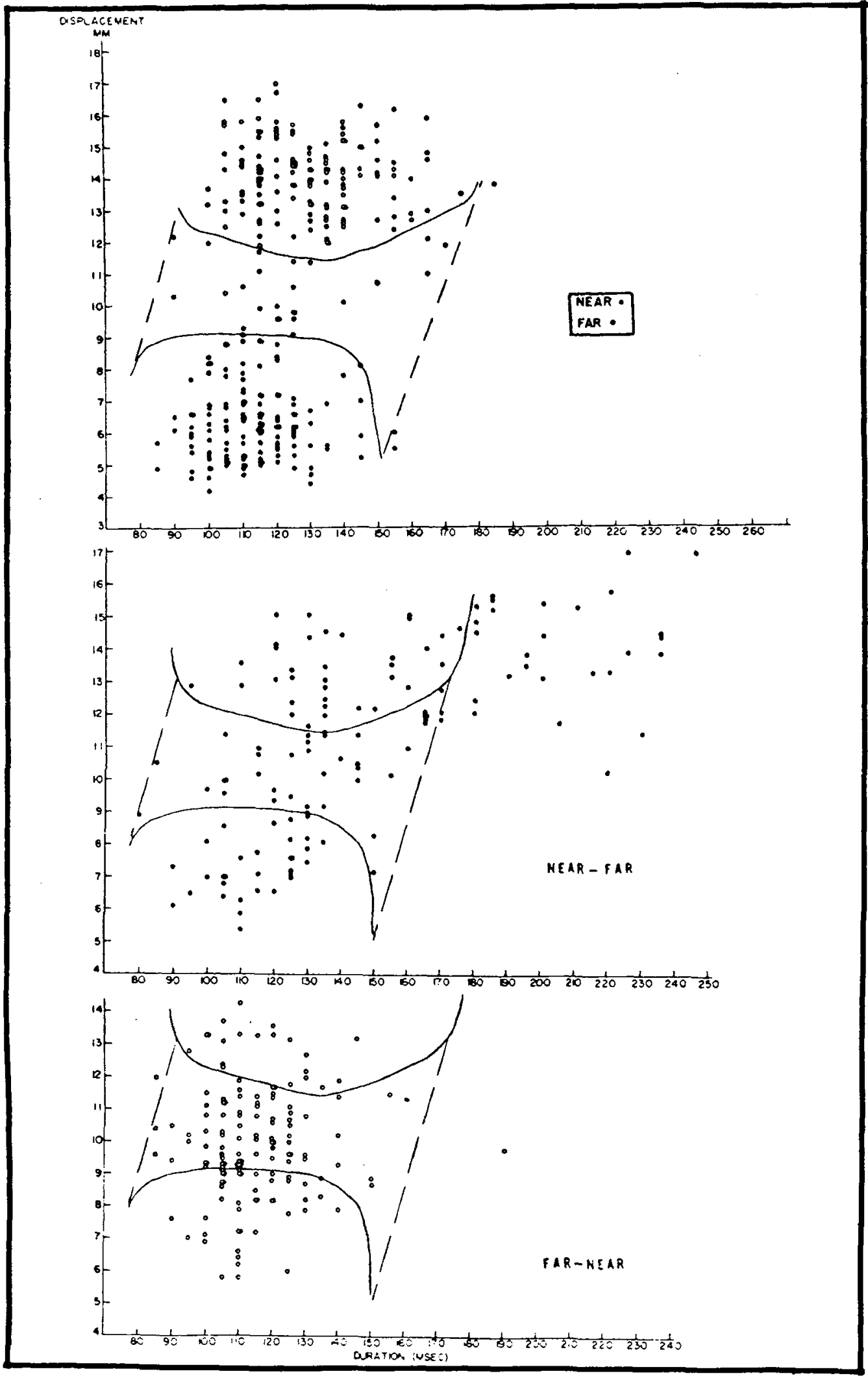

Fig. 4. Scatter plots of maximum displacement against dúration for experimental trials. $S 4$. A sample of near trials and far trials was used and all of the near-far and far-near trials. The contour lines were placed to enclose about 95 ? of the trials on previously drawn samples of the same size of near and far trials. 
were 39 changes from above to below the far median, as compared with only 8 from below to above. ${ }^{5}$

\section{First Discernible Effect of the Second Signal}

In Figure 5, the scatter diagrams of RT against peak positive acceleration are presented for $S 4$. Near and far trials are shown on the top. Near-far trials are in the center and far-near trials on the bottom. The lines connect the median values of acceleration for RT intervals of $20 \mathrm{msec}$ with midpoints of 90,110 , $130 \mathrm{msec}$, etc. The lines for the near and far trials are shown as dotted lines in the other graphs for purposes of comparison.

In the top diagram, it is seen that acceleration is much the same for near and far trials with the short RTs. For RTs of $130 \mathrm{msec}$ and longer, the values diverge. It should be noted that no such delay of separation is obtainable on measures taken later in the response. No matter what the RT, values on near and far trials are clearly separable on velocity and the succeeding measures. We may say that an RT of $130 \mathrm{msec}$ was the shortest on which there were discriminative responses from the onset or shortly thereafter.

Going to the middle diagram where near-far trials are shown. it is seen that at RTs of $170 \mathrm{msec}$ and longer, acceleration for near-far and near trials diverged increasingly. On far-near trials at RTs of $170 \mathrm{msec}$ and longer, there is a reversal of the far trial trend for acceleration to increase.

Thus, the first discernible discriminative responses occurred on both types of corrected trials for an RT of $120 \mathrm{msec}$ in relation to the second signal (170-50). Certainly, it cannot be said that there was any delay in the initial effect of the second signal, the RT for discrimination being about the same as that on uncorrected trials. Similar results were found for Ss 2 and 3 on near-far trials: $130 \mathrm{msec}$ for near and far separation and 110 and $120 \mathrm{msec}$ in relation to the second signal for near-far and near separation. Some
Table 2

Responses Classified According to Near and Far DisplacementDuration Contours (Previous Sample)

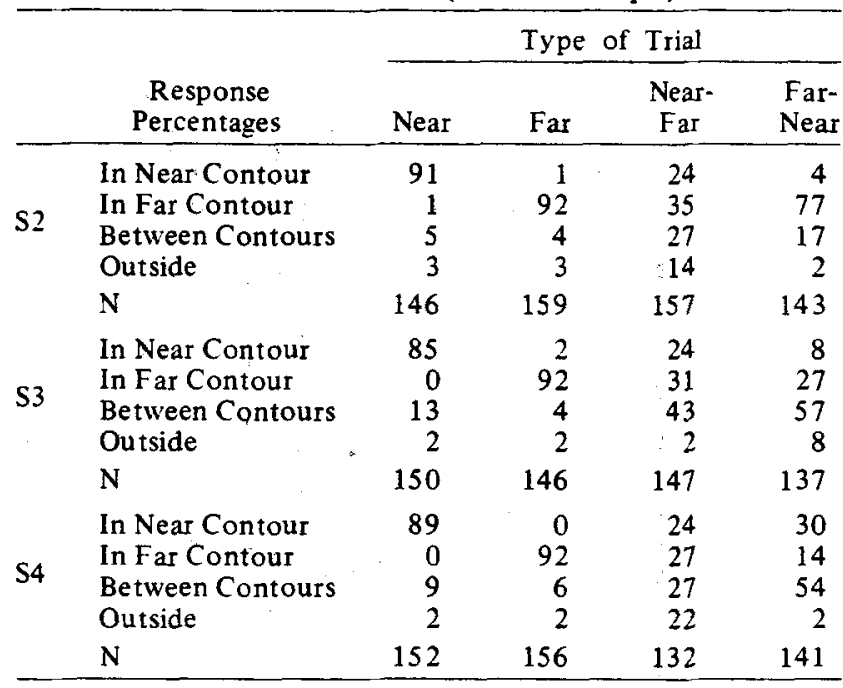

delay was found for these Ss on far-near trials with RTs of 180 and $160 \mathrm{msec}$ in relation to the second signal. However, they both had a near bias at short RTs and so probably had to revise their intention twice, first from near to far. next from far to near.

\section{Correlations}

A consistent pattern of correlations was found between RT and maximum displacement, with one exception. On near trials, the values of the coefficients were $-.201,-.325$, and -.349 for Ss 2,3 , and 4 . respectively. On far trials, the values were $.237, .221$. and .162 . On near-far trials, the values were $.395, .413$, and .289. Finally, on far-near trials, the values were .024 (the exception), -.386 , and -.552 . In general, there was a tendency for the response to be more adequate as RT was longer. It should be noted that $\mathrm{S} 2$ was not very successful in reducing displacement on far-near trials.

Table 3

Cross-Classification of Responses on Corrected Trials: Peak Positive Acceleration and Maximum Displacement

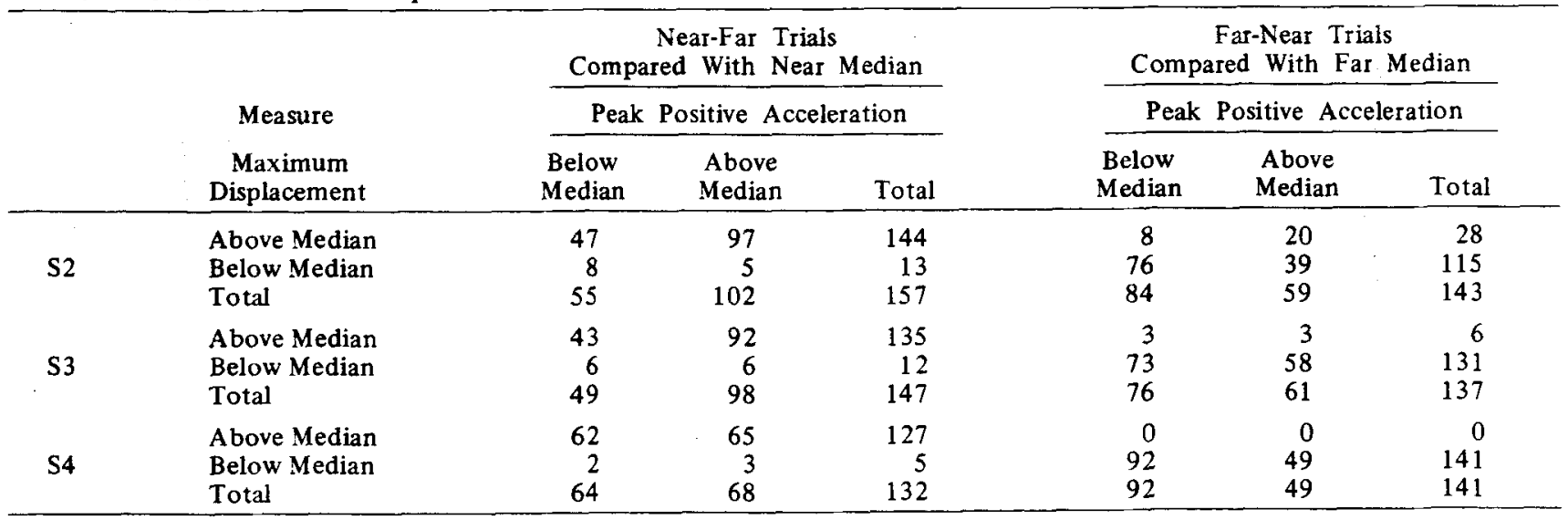


PEMK POSITIVE
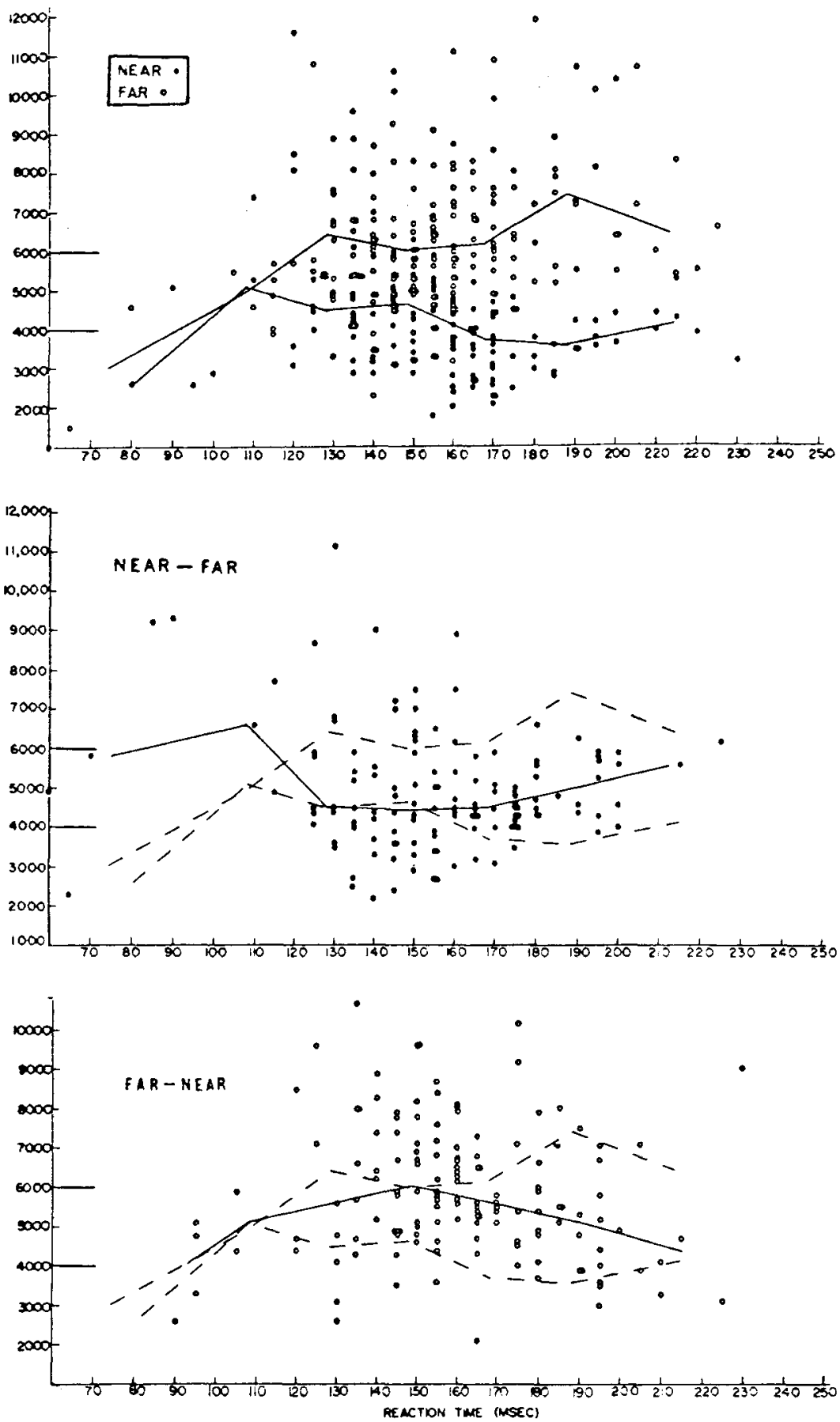

Fig. 5. Scatter plots of peak positive acceleration against RT on experimental trials. S 4. A sample of near trials and far trials was used and all of the near-far and far-near trials. The lines connect the median values of acceleration for RT intervals of $20 \mathrm{msec}$ with midpoints of $90.110 .130 \mathrm{msec}$, etc. In the top diagram. the line which lies above and to the right is for far trials. This line and the near line are shown as dotted lines in the other graphs. 
Fig. 6a. Some illustrative examples of responses.

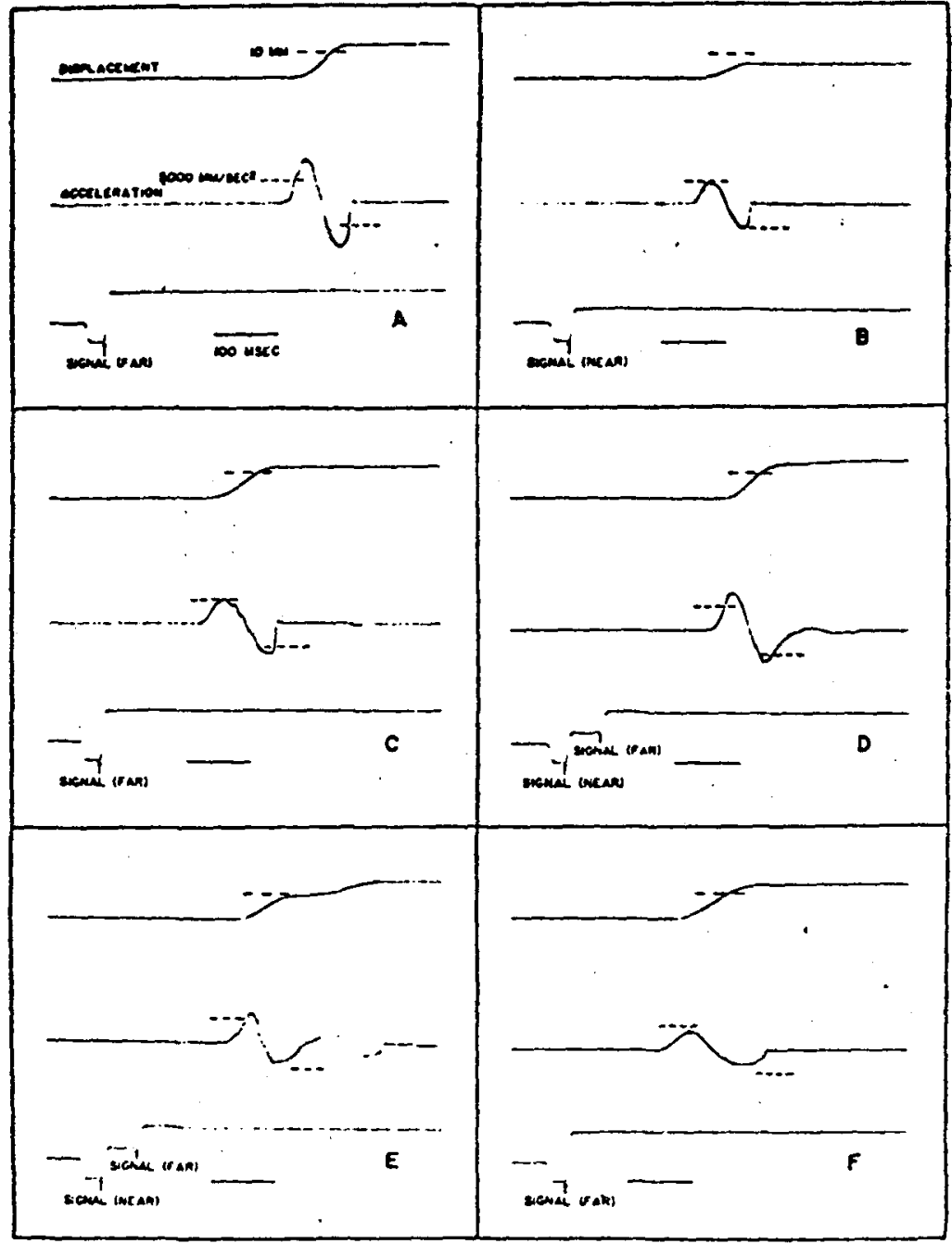

\section{Examples of Responses}

Presented in Fig. 6 are direct recordings from the FM tapes of responses which illustrate the points which have been made. Only displacement and acceleration are shown, since velocity was not recorded directly. The 10 responses will be discussed in the order in which they are shown.

(A) This is a classical far response for $\mathrm{S} 2$, which occurred with a long RT ( $265 \mathrm{msec})$. The value of peak positive acceleration is high $\left(8,921 \mathrm{~mm} / \mathrm{sec}^{2}\right)$, and the displacement is great $(13.6 \mathrm{~mm})$.

(B) RT made no difference for S 2 on starting his near responses. Here is a response with an average RT $(185 \mathrm{msec})$. Low values are found for acceleration $\left(4,150 \mathrm{~mm} / \mathrm{sec}^{2}\right)$ and displacement $(6.3 \mathrm{~mm})$.

(C) When S 2 had a short RT (145 msec) on a far trial, his acceleration was low (here $5,052 \mathrm{~mm} / \mathrm{sec}^{2}$, only slightly higher than in B). However, he still was able to attain a large displacement $(12.4 \mathrm{~mm})$.

(D) With a rather long RT $(210 \mathrm{msec}), \mathrm{S} 2$ produced peak positive accelerations on near-far trials which were often as high as those on far trials (here $8,187 \mathrm{~mm} / \mathrm{sec}^{2}$; compare with A).

(E) Here is a near-far response by $\mathrm{S} 2$ which started with an intermediate value of acceleration $\left(6,508 \mathrm{~mm} / \mathrm{sec}^{2}\right)$, rarely found on near or on far trials. The eventual displacement was also intermediate $(10.0 \mathrm{~mm})$. The initial response process could not be entirely overcome.

(F) This far response, typical of S 3, may be compared with that of $S 2$ in A. It is much less abrupt, with lower acceleration $\left(4,167 \mathrm{~mm} / \mathrm{sec}^{2}\right)$ and longer duration. The same displacement was attained $(13.6 \mathrm{~mm})$.

(G) On a far-near response, S 3 shortened the duration and attained an intermediate displacement $(9.4 \mathrm{~mm})$ after starting with the same acceleration as on the far trial in F. It may be that he was more successful in shortening responses than were Ss 2 and 4 because his initial response was so languid.

(H) Here is a far response typical of S 4 , very much like that of S 2 in A. Duration is moderate, acceleration is fairly high $\left(8,103 \mathrm{~mm} / \mathrm{sec}^{2}\right)$, and displacement is great $(14.5 \mathrm{~mm})$. 


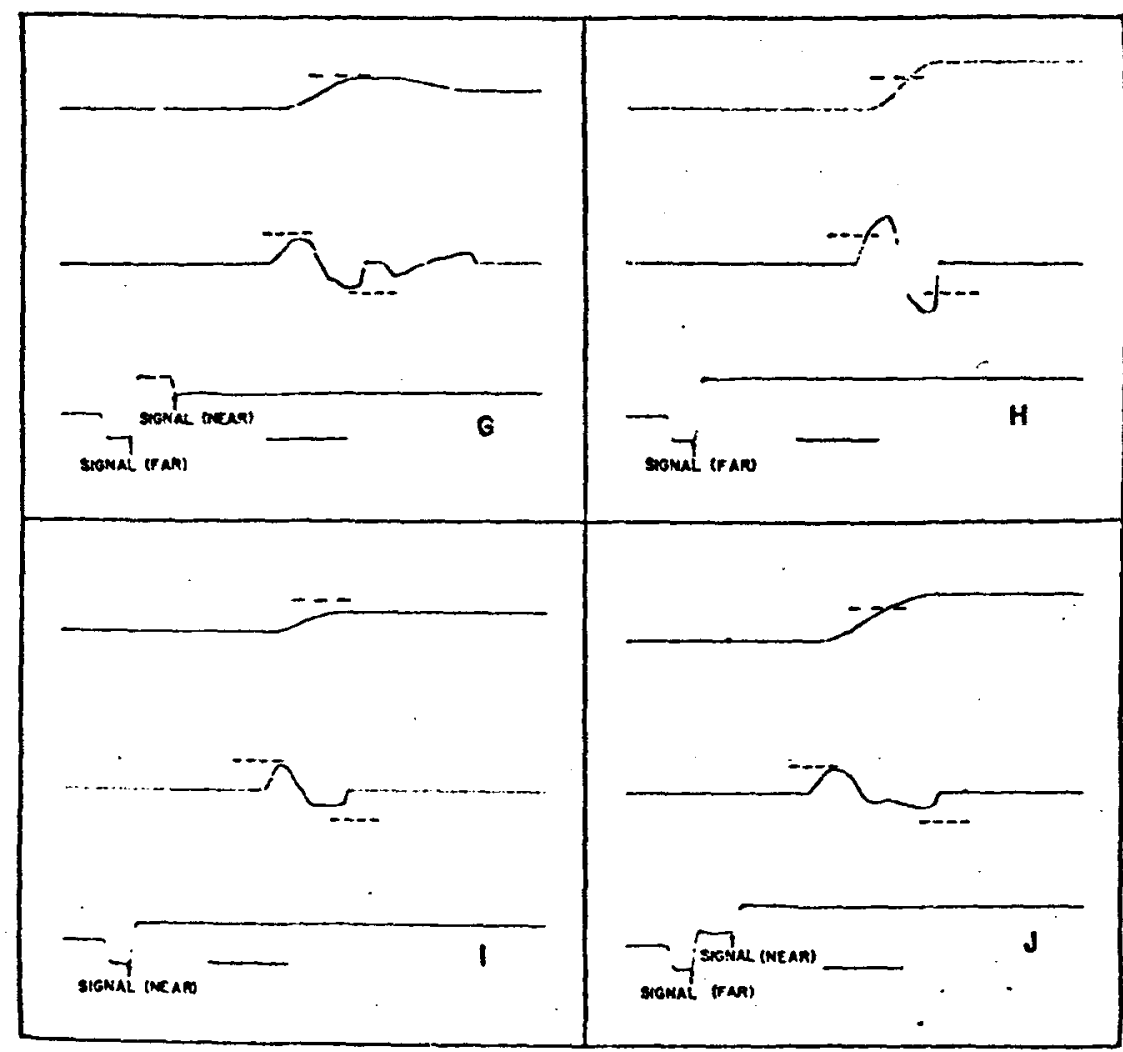

Fig. 6b. Some illustrative examples of responses.

(I) On a near trial, S 4 makes a response not much different in duration from his far response in $\mathrm{H}$. It takes longer than S2's comparable near response in $\mathbf{B}$. Acceleration is low and displacement is small $(6.5 \mathrm{~mm})$.

(J) Here, on a near-far trial, S 4 starts with an acceleration $\left(4,435 \mathrm{~mm} / \mathrm{sec}^{2}\right)$ even lower than his value on the illustrated near trial (I), but stretches out the response to achieve just as large a displacement $(14.7 \mathrm{~mm})$ as on his far trial $(\mathrm{H})$.

\section{DISCUSSION}

The new information on refractoriness of step-tracking responses may be summarized: (1) On some trials the second signal affected response at the first measurable point, peak of positive acceleration. Quite possibly there were responses which were affected from their onset; on a relatively small number of trials, there were responses which appeared to be entirely determined by the second signal. (2) More often than not, the response was modified during its course from its initial "intention." Earlier evidence that a response is completely preformed and therefore invulnerable (Taylor \& Birmingham, 1948) was, in inference, based upon the shape of the acceleration function. (3) Discriminative onset of response to the second signal was discerned for RTs at least as low as $120 \mathrm{msec}$ in relation to that signal. No lower value was found for the earliest discriminative onset on uncorrected trials in relation to the first signal. Thus, there seems to have been no delay in an effect of the second signal.

Previous findings that the response was typically intermediate between the requirements of the two signals (Vince, 1948; Gottsdanker, 1966) were corroborated. S's difficulty in producing a satisfactory response to the second signal cannot be attributed to the informational processing of the first signal since, as noted, there was little, if any, delay in utilizing the information in response and, perforce, none in the stages of identification or selective decision on an action (Welford, 1971, p. 119). Instead, there must have been interference from a response process which could not be entirely overcome. From the present findings, it cannot be determined whether the resistance was in the neural organizing, the contraction-relaxation states assumed by the muscles, or in the inertia of the limb and control. The possibility of a resistant neural organizing process is the most interesting. If such a process interferes with all other neural organizing of responses, it could account for the PR found when different response units are employed. Since considerable mobilization of response is required to close a switch, the effect would show up as a delay in RT2.

In this study, as in the ones cited previously on step-tracking, responses were more adequate as RT was longer. Moreover, here, where all responses were in the same direction, the same was true of uncorrected responses. This relationship cannot be accounted for by a tendency to wait, conscious or unconscious. The addition of corrected trials did not change RT over the 
control condition. where there were only uncorrected trials. There are two implications of the relationship. First, a good portion of the RT interval remained open to new information. Second, there were other determiners of RT than discrimination. Level of preparation at the instant of the signal is such a possibility. Responses appeared to be initiated with whatever information was available at the time. With only the choice between near or far response, it was almost always possible to arrive at a successful displacement on uncorrected trials, even with an inappropriate start. The previous finding by the writer (1969) that near-far choice had about the same RT as simple RT to near or far is now clarified.

The major concern of research on $P R$ in connection with tracking is whether the human operator is continuous or intermittent in relating his response to environmental information. It should be stressed, even if the present conclusion is accepted-that there is no delay in influence on response of a second signal-the relation may still be intermittent. In a sequence of only two signals, $\mathrm{S}$ was usually unable to make an effective response to the second. His responses fell short of the new requirement and were of ten distorted in form. With a continuous flow of signals. S may be unwilling to expend his effort to no avail and so may become voluntarily intermittent. This reasoning may be extended to sequential discrete activities with even better justification. In these cases, it is not usually important to make responses as quickly after the signal as possible; reproducing the correct order is what counts.

Data could not be analyzed exactly as anticipated. One reason is that the effect of the second signal was not uniform. The initial influence occurred both at the onset of a response and during a response. Also, it was not foreseen that near and far responses would overlap so much in their initiation, found here particularly with short RTs. Clear-cut types of responses simply did not emerge, making any method of averaging whole responses misleading. Possibly better control of effects and improved precision of measurement would have been obtained with a different selection of responses. However, the two earlier studies of step-tracking were far from successful in their selections. Vince used an occasional return to the home position as a second signal. If the response was controlled by the second signal, this left nothing to be measured. The writer had used a reversing signal as well as a curtailing one. A serious problem was in deciding whether small irregularities in the direction of the first signal were simply noise or a strongly curtailed response. Also, the distance between signal positions introduced unwanted perceptual and attentional variables.

\section{REFERENCES}

Gottsdanker, R. The effect of superseding signals. Quarterly Journal of Experimental Psychology, 1966, 21, 236-249.

Gottsdanker. R. Computer determinations of the effect of superseding signals. Acta Psychologica, 1967, 27, 35-44.
Gottsdanker. R. Choice reaction time and the nature of the choice response. Psychonomic Science. 1969, 14, 257-258.

Tavlor. F. V..\& Birmingham, H. P. Studies of tracking behavior: il. The acceleration pattern of quick manual corrective responses. Journal of Experimental Psychology, 1948, 38 , 783-795.

Vince. M. A. The intermittency of control movements and the psychological refractory period. British Journal of Psychology, 1948. 38, 149-157.

Wallis, W. A.. \& Roberts, H. V. Statistics: A new approach. Glencoe. I1l: The Free Press, 1956.

Welford, A. T. Fundamentals of skill. (Rev. ed.) London: Methuen. 1971.

\section{NOTES}

1. For details of the treatment of data, a complete table of results. distributions. and a number of graphs, omitted here because of the limitations of space, order Document No. P401 from Publications Office. Psychonomic Society, 1018 West 34 th Street, Austin, Texas 78705 , remitting $\$ 5.00$ for a set of photocopies.

2. On all comparisons. the means of maximum displacement on the near-far and far-near trials were significantly different from both the near and the far means. It may be seen in Table 1 that on the corrected trials, the largest SD was $2.94 \mathrm{~mm}$ ( $\mathrm{S} 2$ on near-far trials) and the smallest $\mathrm{N}$ was 132 (S 4 on near-far trials). Taking these two values together gives a maximum estimate of the 0.99 confidence interval: $0.67 \mathrm{~mm}$. The smallest difference for any $\mathrm{S}$ between a corrected and an uncorrected mean, by far. was found in comparing $S 2$ 's maximum displacement on near-far trials, $11.9 \mathrm{~mm}$, and on far trials, $13.2 \mathrm{~mm}$. This difference is $1.3 \mathrm{~mm}$.

3. On all comparisons except one, the means of peak positive acceleration on the near-far and far-near trials were significantly different from both the near and the far means. It may be seen in Table 1 that, for S 3 , the values on the far-near and far trials were very similar: $3,646.4$ and $3,696.2 \mathrm{~mm} / \mathrm{sec}^{2}$. The next smallest difference was for the same $S$ in comparing near-far and near trials, a value of $403.1 \mathrm{~mm} / \mathrm{sec}^{2}$. It is further seen in Table I that the largest $\mathrm{SD}$ was $1,829.88 \mathrm{~mm} / \mathrm{sec}^{2}$ (S 2 on far-near trials) and the smallest $N$ was 132 (S 4 on near-far trials). Taking these last two values together gives a maximum estimate of the 0.99 confidence interval on corrected trials: $410.2 \mathrm{~mm} / \mathrm{sec}^{2}$. The remaining 10 of the 12 differences are far bey ond this value.

4. Two kinds of statistical test were made. The first compared the S's near-far trials with his near trials or his far-near trials with his far trials as to the proportion which departed from the category of the initial (or only) signal. The second test made the same comparison as to the proportion of trials which were within neither the near nor the far contours. Only in the case of S 2 on far-near trials were the compared values at all close. In respect to the percentage departing from the far contour, the values were $23 \%$ on far-near trials and $8 \%$ on far trials. In respect to the percentage being within neither contour, the values were $19 \%$ on far-near trials and $7 \%$ on far trials. Even this smallest difference provided a value of $Z$, the normal deviate, of 3.2 $(\mathrm{p}<.001)$ in the test for comparing proportions (Wallis \& Roberts, p. 429).

5. This second case, which provides the smallest difference in the six tables for the three Ss, had high statistical significance. Using the test for two matched sample proportions (Wallis \& Roberts, p. 431), the normal deviate $Z=4.4(p<.001)$. In all cases, then, the percentage of trials modified by the second signal must have increased between the onset and the end of the response.

(Received for publication June 28, 1972; revision received December 27,1972 ; accepted March 20, 1973.) 